\title{
PROTEÇÃO AO PATRIMÔNIO ESPELEOLÓGICO NO CEARÁ: GRUTA CASA DE PEDRA
}

\author{
Felipe Antônio Dantas Monteiro ${ }^{(a)}$, Doris Day Santos da Silva ${ }^{(b)}$, Andréa de Sousa Moreira ${ }^{(c)}$, \\ Pedro Edson Face Moura ${ }^{(d)}$
}

(a) Secretaria do Meio Ambiente do Estado do Ceará - SEMA, fm.meioambiente@ gmail.com

(b) Secretaria do Meio Ambiente do Estado do Ceará - SEMA, doris.santos@sema.ce.gov.br

(c) Secretaria do Meio Ambiente do Estado do Ceará - SEMA, andrea.moreira@ sema.ce.gov.br

(d) Programa de Pós-graduação em Geografia, Universidade Federal do Ceará - UFC, pedroedson18@ gmail.com

Eixo: GEODIVERSIDADE, GEOARQUEOLOGIA E PATRIMÔNIO NATURAL

\begin{abstract}
Resumo
Estão sendo desenvolvidas no Ceará, ações para a proteção do patrimônio espeleológico, tendo como destaque a gruta Casa de Pedra. Este artigo aborda as experiências, atuações e propostas da participação direta da Secretaria do Meio Ambiente - SEMA, no Grupo de Trabalho relativo à proteção ao patrimônio espeleológico no Estado do Ceará (GT de Espeleologia). A gruta Casa de Pedra, localizada no município de Madalena, foi escolhida como projeto piloto do referido GT, por esta sendo alvo de significativos impactos ambientais. Objetiva-se com o presente trabalho, expor as possíveis soluções para os problemas ambientais relacionados a esta cavidade natural subterrânea. Para a elaboração do artigo, realizou-se o levantamento e estudo bibliográfico de publicações relacionadas, pesquisou-se o histórico de origem e andamento das atividades e discussões do GT de Espeleologia e as ações da SEMA nesta seara. Por fim, expõem-se as propostas de ação discutidas para a proteção do patrimônio espeleológico.
\end{abstract}

Palavras chave: Caverna; Patrimônio Espeleológico; Secretaria do Meio Ambiente (SEMA); Ceará; Casa de Pedra.

\section{Introdução}

A Secretaria do Meio Ambiente do Estado do Ceará - SEMA está desenvolvendo importantes ações objentivando à proteção de cavernas no território cearense. Em parceria com o Ministério Público Estadual - MPE-CE formaram um Grupo de Trabalho com vistas à efetivação da proteção do patrimônio espeleológico no estado (GT de Espeleologia), tendo como projeto piloto a gruta Casa de Pedra, no município de Madalena.

A cerca de $180 \mathrm{~km}$ de Fortaleza, está localizada a caverna Casa de Pedra, no município de Madalena, próximo à divisa com o município de Itatira. Escolhida como projeto piloto do já mencionado Grupo de Trabalho, esta cavidade natural subterrânea atualmente está sendo alvo de significativos impactos ambientais, sofrendo vandalismo, com mais de uma centena de pichações na entrada e no seu interior, e 


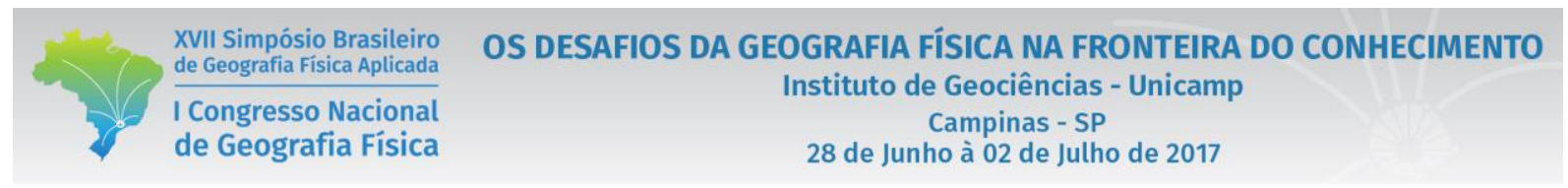

poluição do ambiente cavernícola com a marcante presença de resíduos sólidos descartados na cavidade, consequências de visitações eventuais de pessoas ao local.

Este artigo tem como objetivo apresentar o atual estudo de caso pertinente a gruta Casa de Pedra, abordando as experiências, ações e propostas da participação direta da SEMA no Grupo de Trabalho relativo à proteção ao patrimônio espeleológico no Estado do Ceará, que é capitaneado pelo Ministério Público Estadual.

\section{Metodologia}

Para o desenvolvimento desta pesquisa, que expõem o estudo de caso, das ações para proteção do patrimônio espeleológico no Ceará, especialmente na gruta Casa de Pedra, e discussão sobre soluções relativas aos seus problemas ambientais, o arcabouço teórico-metodológicos foi norteado pelo levantamento e estudo bibliográfico de publicações relacionadas ao assunto, com destaque para a legislação brasileira pertinente à espeleologia. Tendo em sua continuidade, a pesquisa do histórico de origem e evolução do Grupo de Trabalho (GT) de Espeleologia e as ações da SEMA nesta seara. Seguido pela análise do andamento das atividades e discussões do referido GT. Ao final, expõem-se as propostas de ação discutidas para o caso da gruta Casa de Pedra.

\section{Resultados e Discussão}

No Brasil, existe um conjunto de normas legais pertinentes à proteção das cavidades naturais subterrâneas e do patrimônio espeleológico brasileiro. A propria Constituição Federal de 1988, no Art. 20, inciso X, elenca as cavidades naturais subterrâneas, como um dos "bens da União" (MONTEIRO, 2014). No Decreto Federal no 99.556/1990 cita-se a definição de cavidades naturais subterrâneas.

Entende-se por cavidade natural subterrânea todo e qualquer espaço subterrâneo acessível pelo ser humano, com ou sem abertura identificada, popularmente conhecido como caverna, gruta, lapa, toca, abismo, furna ou buraco, incluindo seu ambiente, conteúdo mineral e hídrico, a fauna e a flora ali encontrados e o corpo rochoso onde os mesmos se inserem, desde que tenham sido formados por processos naturais, independentemente de suas dimensões ou tipo de rocha encaixante. (BRASIL, 1990)

O referido Decreto Federal dispõe sobre a proteção das cavernas existentes no Brasil, no texto original do seu Art. $5^{\circ}$, apresentava-se o seguinte conceito de patrimônio espeleológico, "conjunto de elementos bióticos e abióticos, socioeconômicos e histórico-culturais, subterrâneos ou superficiais, representados pelas cavidades naturais subterrâneas ou a estas associados". Com a publicação do Decreto Federal $n^{\circ}$ 
XVII Simpósio Brasileiro OS DESAFIOS DA GEOGRAFIA FÍSICA NA FRONTEIRA DO CONHECIMENTO

Instituto de Geociências - Unicamp

Campinas - SP

Congresso Nacional

de Geografia Física

28 de Junho à 02 de Julho de 2017

6.640/2008, este último fez alterações na redação original do decreto anterior, suprimindo o conceito de patrimônio espeleológico (MONTEIRO, 2014a).

Mas a definição de patrimônio espeleológico na legislação ambiental brasileira, ainda está mantida na Resolução do Conselho Nacional de Meio Ambiente - CONAMA no 347/2004, que dispõe sobre a proteção do patrimônio espeleológico. Nesta resolução, em suas considerações, afirma-se que "as cavidades naturais subterrâneas compõem o Patrimônio Espeleológico Nacional", e no Art. $2^{\circ}$ o conceito de patrimônio espeleológico é idêntico ao da redação original do Decreto $n^{\circ}$ 99.556/1990. Também merece destaque no mesmo artigo da Resolução do CONAMA, a definição de área de influência sobre o patrimônio espeleológico que é conceituado como "área que compreende os elementos bióticos e abióticos, superficiais e subterrâneos, necessários à manutenção do equilíbrio ecológico e da integridade física do ambiente cavernícola" (CONAMA, 2004).

Para um melhor dimensionamento e compreensão do desenvolvimento deste trabalho, demonstra-se relevante fazer o levantamento histórico da origem do estudo de caso, da gruta Casa de Pedra e do já citado GT de Espeleologia, que trata da proteção do patrimônio espeleológico do território cearense, que estão intrinsecamente ligados.

O antigo Conselho de Políticas e Gestão do Meio Ambiente - CONPAM, atualmente Secretaria do Meio Ambiente - SEMA, do Estado do Ceará, que tem uma coordenação técnica responsável pela conservação da Biodiversidade no estado, a Coordenadoria de Biodiversidade - COBIO, recebeu em abril de 2014, um ofício do MPE-CE, solicitando um técnico especialista em espeleologia (estudo de cavernas) para realizar uma vistoria, com o objetivo de averiguar as questões acerca da proteção do patrimônio espeleológico da caverna Casa de Pedra no município de Madalena, que vem sofrendo degradação ambiental. A COBIO providenciou reunir-se com o MPE-CE para discutir a questão, apresentando a importancia do Patrimônio Espeleológico no Estado do Ceará e propostas de ações para a sua proteção. Após as discussões sobre a temática, fico estabelecido a realização de uma reunião no MPE-CE com todas as instituições públicas relacionadas à proteção do Patrimônio Espeleológico. Tendo-se como proposta a formação de um Grupo de Trabalho para tratar das ações necessárias para garantir a efetivação da proteção do Patrimônio Espeleológico no Estado do Ceará, e como projeto piloto da atuação deste GT de Espeleologia, o caso de degradação ambiental da caverna Casa de Pedra, que propiciou a origem destas discussões e trabalhos.

Em julho de 2014, realizou-se a primeira reunião do GT de Espeleologia, na sede do Centro de Apoio Operacional de Proteção à Ecologia, Meio Ambiente, Urbanismo, Paisagismo e Defesa do Patrimônio Histórico, Artístico e Cultural - CAOMACE, do MPE-CE, que contou com a participação do CONPAM, da Superintendencia Estadual do Meio Ambiente - SEMACE, do Instituto Brasileiro do Meio Ambiente e 


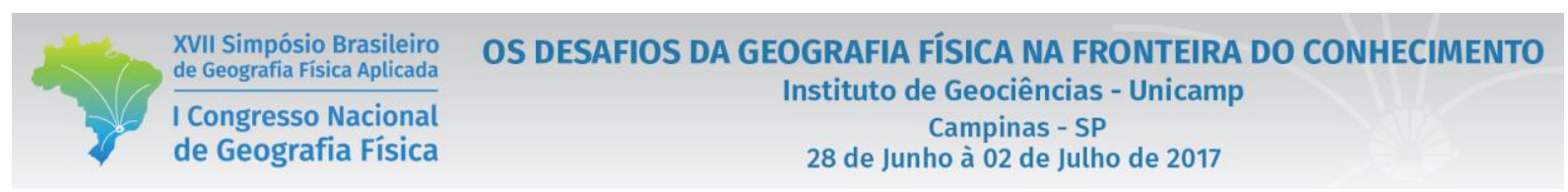

dos Recursos Naturais Renováveis - IBAMA, do Instituto do Patrimônio Histórico e Artístico Nacional IPHAN, do Departamento Nacional de Produção Mineral - DNPM, da Companhia de Pesquisa de Recursos Minerais - CPRM, do Batalhão de Polícia Militar Ambiental - BPMA, e de um professorespeleólogo do Departamento de Geologia da Universidade Federal do Ceará - UFC.

Como ações iniciais do GT de Espeleologia, definiu-se uma vistoria técnica conjunta do CONPAM e equipe de espeleologia do Departamento de Geologia da UFC, à gruta Casa de Pedra para o reconhecimento deste patrimônio espeleológico e providenciar o cadastramento da referida cavidade natural subterrânea junto ao Centro Nacional de Pesquisa e Conservação de Cavernas - CECAV, do Instituto Chico Mendes de Conservação da Biodiversidade - ICMBio.

Art. 5-B. Cabe à União, por intermédio do IBAMA e do Instituto Chico Mendes, aos Estados, ao Distrito Federal e aos Municípios, no exercício da competência comum a que se refere o art. 23 da Constituição, preservar, conservar, fiscalizar e controlar o uso do patrimônio espeleológico brasileiro, bem como fomentar levantamentos, estudos e pesquisas que possibilitem ampliar o conhecimento sobre as cavidades naturais subterrâneas existentes no território nacional. (BRASIL, 2008)

Nos dias 18 e 19 de setembro de 2014, o CONPAM realizou uma vistoria técnica conjunta com a equipe da Geologia da UFC, na gruta Casa de Pedra no município de Madalena-CE. Na ocasião procedeu-se a coleta de dados para o devido cadastramento da caverna no CECAV. Como resultado do trabalho de campo, a equipe da UFC elaborou o Mapa de Registro de Cavidades Naturais (Figura 1), contendo a localização, as vias de acesso, os detalhes do local das cavidades naturais, contorno aproximado do afloramento rochoso e as 3 (três) entradas de cavidade encontradas, existindo a possibilidade de que as entradas estejam conectadas formando uma única cavidade natural subterrânea. Portanto, para efeitos deste trabalho, será tratado aqui como se houvesse apenas uma cavidade/caverna, "Casa de Pedra".

Segundo o relato do professor-espeleólogo do Departamento de Geologia da UFC, que participou da vistoria técnica, a gruta Casa de Pedra está situada em uma lente carbonática existente na região e pode ser considerada uma das maiores cavidades naturais subterrâneas de formação litológica em Mármore do Estado do Ceará. 


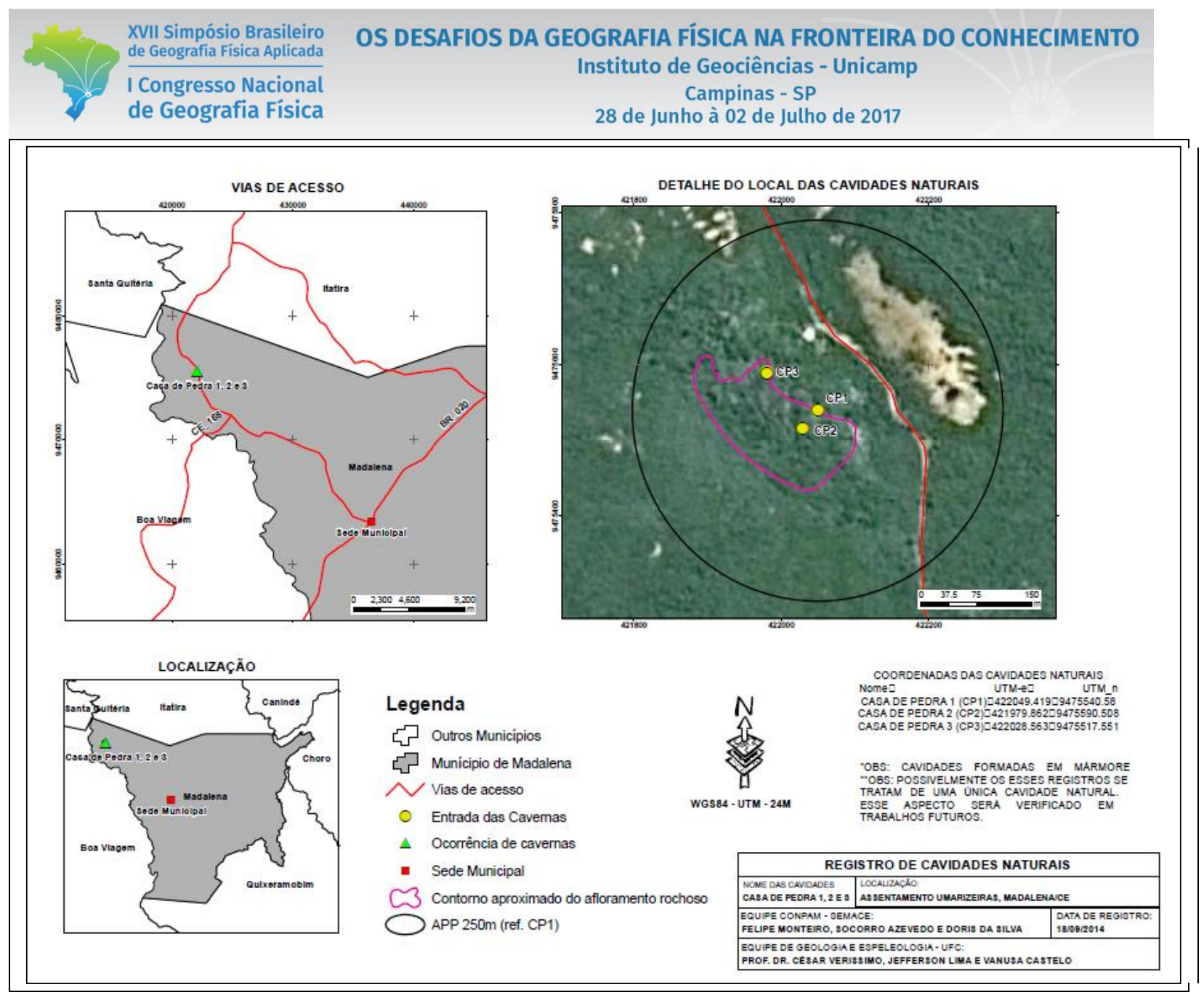

Fonte: Veríssimo et al (2014)

Figura 1 - Mapa de registro de cavidades naturais subterrâneas, Casa de Pedra em Madalena-CE.

Nesta inspeção técnica em campo foi possível constatar a situação de expressiva degradação em que se encontra a Casa de Pedra, a imensa quantidade de pichações feitas nas paredes da cavidade, no seu interior, como principalmente em sua entrada, superior a uma centena delas, de vários tamanhos, feitas com corretivo escolar e até mesmo com spray de tinta a óleo, cuja fixação é bem maior e a remoção mais difícil. É extremamente perceptível o impacto visual provocado pelas pichações em vastas partes da cavidade e principalmente em sua entrada, além de resíduos sólidos (garrafas pet de refrigerante e de água, papel, embalagens plásticas e etc.) dispostos dentro da cavidade natural subterrânea e vestígios da ocorrência de fogueiras (Figuras 2 a 5). 


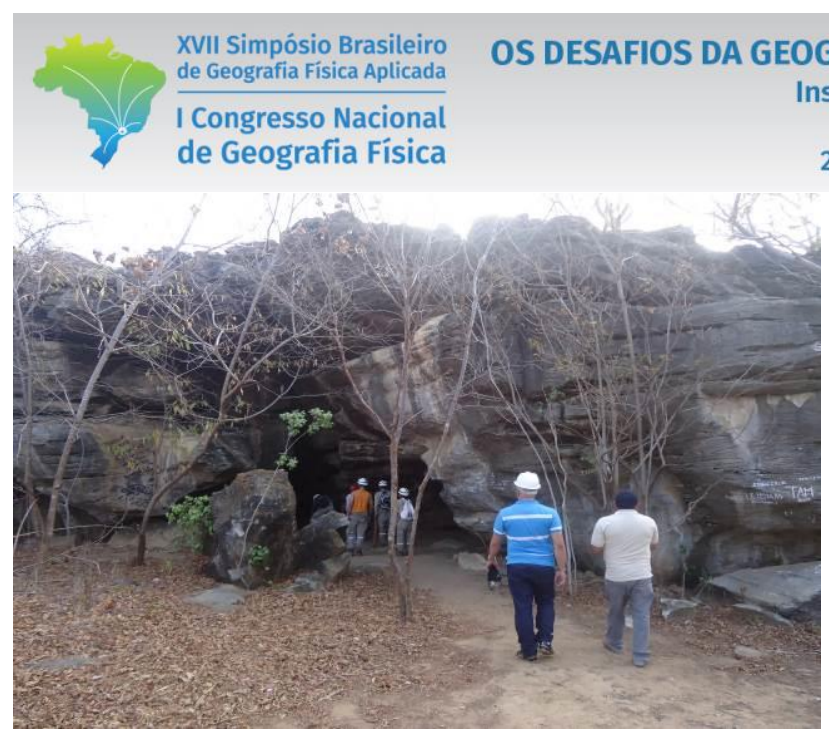

Figura 2 - Entrada principal da cavidade.

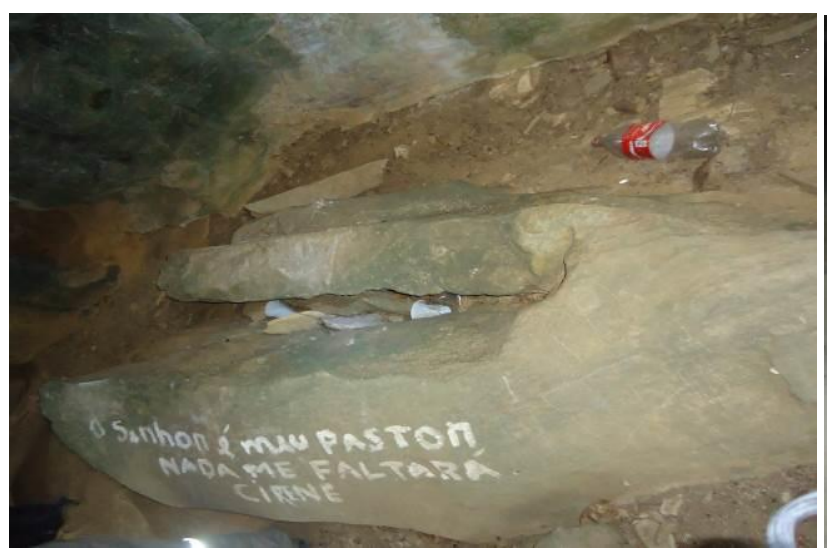

Figura 4 - Pichações e descarte de lixo.

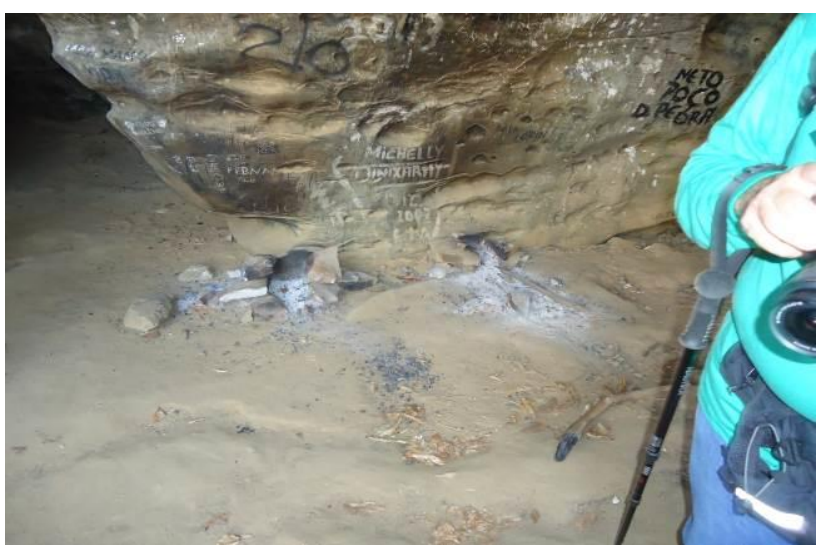

Figura 5 - Vestígios de fogueiras e mais pichações.

As condições encontradas na Casa de Pedra são típicas dos impactos decorrentes das visitações eventuais às cavernas, que foram estudadas por Ferreira (2013) em "Análise de impactos ambientais em terrenos cársticos e cavernas".

Uma variação bastante danosa de visitação a cavernas é aquela praticada geralmente de forma eventual, não sistemática, sem controle e que resulta em vandalismo. Geralmente manifesta-se através das pichações, quebra de espeleotemas e demais formações, roubo de fósseis, ataque à fauna, lixo e, até mesmo, a queima de fogos de artifício em seu interior.

Algumas cavernas brasileiras foram totalmente descaracterizadas por esta ação, como por exemplo, a Gruta do Catingueiro em Lagoa da Prata-MG, ou a Gruta da Faustina, em Pedro Leopoldo-MG. Esta última está localizada às margens de uma rodovia movimentada e seu pórtico de entrada é chamativo, pelo tamanho, talvez por isso tendo sido tão depredada. (FERREIRA, 2010) 


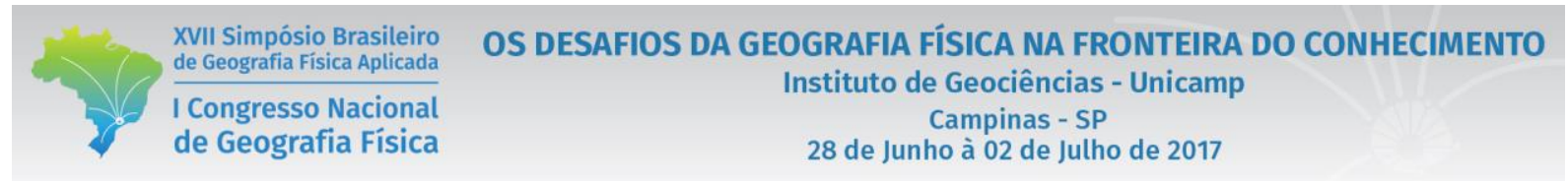

São várias as modalidades existentes de atividades de visitação à cavernas, podem-se destacar as visitações de turismo de massa, de turismo religioso, visitações eventuais, de exploração, pesquisa e aventura. As visitações eventuais às cavernas, tem se demonstrado em geral bastante prejudiciais às cavidades naturais subterrâneas, pois ocorrem comumente sem nenhum cuidado e respeito ao meio ambiente. (MONTEIRO, 2014)

As atividades de visitação, em suas diversas formas, constituem importante ferramenta de educação e, de sensibilização, mas em muitos casos, se transformou em meio de destruição. Muitas cavernas foram descaracterizadas através desta prática.

Vale lembrar que, as cavernas são recursos naturais não renováveis, elas se formaram com o passar de muito tempo, de muita água. Portanto, apesar de benéfica em muitos casos, a atividade de espeleoturismo deve ser bem pensada a fim de resultar em ganhos na conservação destes ambientes, em conhecimento acerca do seu funcionamento e não apenas em recreação descompromissada.

(FERREIRA, 2013)

Por deliberação do GT de Espeleologia foram realizadas audiências públicas na região da gruta Casa de Pedra, no dia 10 de junho de 2015 no município de Madalena, e no dia 11 no distrito de Lagoa do Mato no município de Itatira, com a presença dos promotores do MPE-CE, da SEMA, SEMACE, IPHAN, BPMA, CPRM, representante da Sociedade Brasileira de Espeleologia - SBE, das respectivas prefeituras, vereadores, associações, comunidades, professores e estudantes, objetivando que a população pudesse tomar conhecimento da caverna e da sua situação, e explicar a importância da preservação do patrimônio espeleológico da região, pois muitas pessoas da comunidade pouco conheciam sobre esta gruta.

No mesmo período das audiências públicas, uma equipe de espeleólogos da Geologia da UFC, SEMA e SBE e o IPHAN realizaram um trabalho de campo na gruta, sendo detectada a ocorrência de novas pichações com tinta à base de óleo, inclusive em blocos rochoso com registros arqueológicos. Com a orientação técnica do IPHAN, a prefeitura de Madalena providenciou colocar sobre estes blocos rochosos uma lona plástica, sobreposta por um anel de concreto cheio de pedras e areia, para proteger os registros arqueológicos encontrados na gruta (Figuras 6 e 7). 


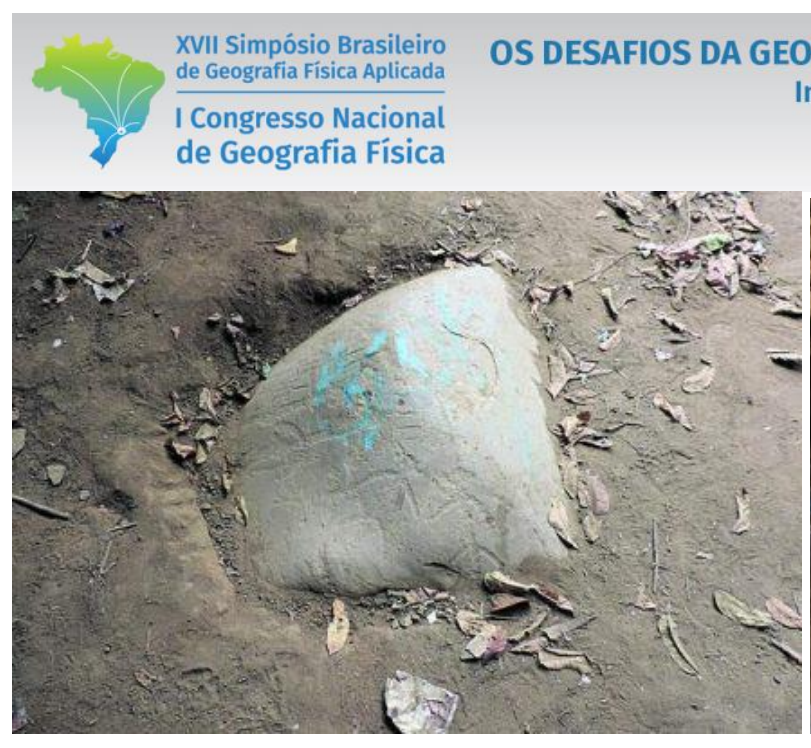

Figura 6 - Inscrições rupestres com pichação.
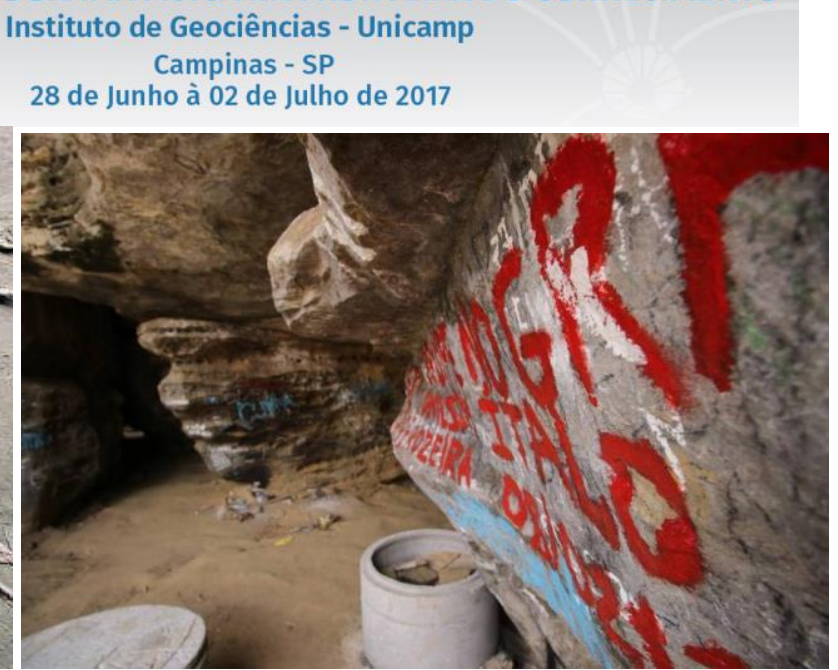

Figura 7 - Aneis de concreto para proteção.

Os trabalhos desenvolvidos pelo GT de Espeleologia na gruta Casa de Pedra têm despertados a atenção dos meios de comunicação no estado do Ceará, sendo realizadas entrevistas e reportagens com integrantes do GT e na Casa de Pedra, pela TV Diário, TV Cidade, Rádio FM Jangadeiro, Jornal O Estado, Jornal O Povo e outros blogs e sites (Figuras 8 e 9).

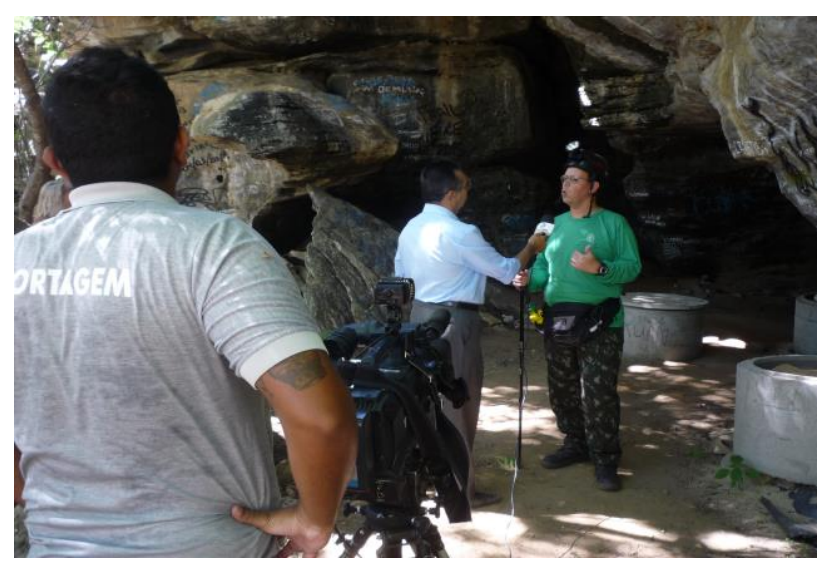

Figura 8 - Gravação de reportagem.

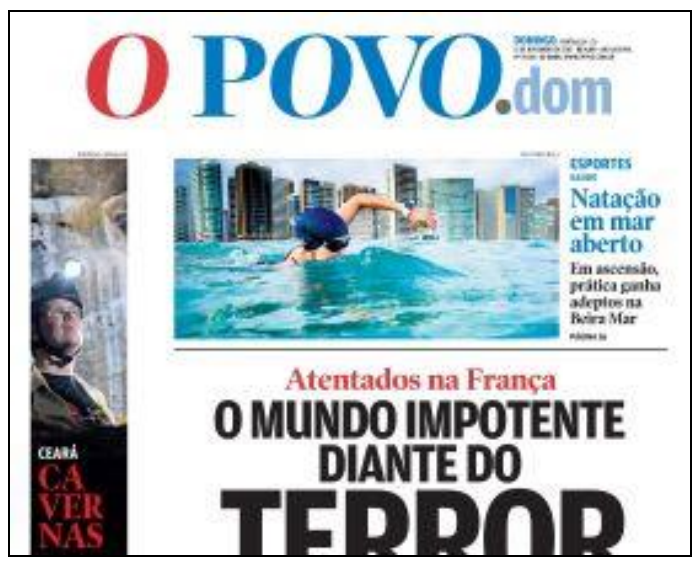

Figura 9 - Matéria de capa do jornal O Povo.

Diante do ocorrido, o GT de Espeleologia discutiu sobre a necessidade de realizar projetos para avançar nos estudos espeleológicos, arqueológicos e ambientais, e desenvolver ações de educação ambiental e proposta de criação de uma Unidade de Conservação na área da gruta Casa de Pedra. Tendo-se conhecimento sobre a possibilidade de inscrição de projetos para seleção no edital do Fundo de Defesa dos Direitos Difusos do Estado do Ceará - FDID, do MPE-CE, algumas das instituições integrantes do GT de Espeleologia se interessaram em participar deste certame. 
XVII Simpósio Brasileiro

de Geografia Fisica Aplicada

I Congresso Nacional

de Geografia Física
OS DESAFIOS DA GEOGRAFIA FÍSICA NA FRONTEIRA DO CONHECIMENTO

Instituto de Geociências - Unicamp

Campinas - SP

28 de Junho à 02 de Julho de 2017

Inscreveram-se no Edital $n^{\circ}$ 03/2015 do FDID, três projetos relacionados à gruta Casa de Pedra: a SEMA com o projeto "Proteção e Conservação da Gruta Casa de Pedra", para desenvolver ações de educação ambiental na região e realizar estudos e trabalhos técnicos para analisar a viabilidade para criação de Unidade de Conservação na área da gruta; o IPHAN-CE com o projeto "O Homem e o Ambiente na Préhistória do Ceará Central", visando fazer o estudo arqueológico da gruta e o seu respectivo levantamento técnico; e o Departamento de Geologia da UFC com o projeto "Estudando e Conservando a Gruta Casa de Pedra", com o objetivo de realizar os estudos geológicos e espeleológicos da cavidade e seu entorno, inclusive com o mapeamento 3D da gruta. Em janeiro de 2016 foi divulgado o resultado do edital de seleção do FDID, com a aprovação de três projetos relativos à gruta Casa de Pedra. Desses, a UFC e o IPHAN, por questões burocráticas não assinaram o contrato para execução dos projetos com o FDID. A SEMA conseguiu celebrar o convênio, e atualmente está com o projeto em execução, passando pelas etapas de elaboração de Termo de Referência para contratação dos serviços de consultoria e demais procedimentos inerentes aos trâmites licitatórios.

\section{Considerações finais}

Atualmente, existe no Ceará um Grupo de Trabalho de Espeleologia, capitaneado pelo MPECE/CAOMACE com apoio direto da SEMA, integrado por instituições como SEMACE, IBAMA, IPHAN, DNPM, CPRM, BPMA, Departamento de Geologia da UFC, e SBE, que visa tratar das ações necessárias para garantir a efetivação da Proteção do Patrimônio Espeleológico no Estado do Ceará. Esta integração do GT de Espeleologia possibilita a realização de reuniões periódicas para discutir e deliberar sobre questões pertinentes e conduz o desenvolvimento de ações, que buscam dar maior atenção a proteção as cavernas no território cearense.

O GT de Espeleologia, de forma experimental, tem no presente como projeto piloto a gruta Casa de Pedra no município de Madalena, próximo à divisa com o município de Itatira, destaca-se por ter um significativo Patrimônio Espeleológico, inclusive com a existência de importantes registros arqueológicos no seu interior, segundo o IPHAN. Mas este patrimônio encontra-se bastante degradado pela ação depredadora de dezenas de pichações e poluição neste relevante ambiente cavernícola.

Diante desta situação, o GT de Espeleologia e alguns de seus integrantes vêm desenvolvendo ações na perspectiva de solucionar os problemas ambientais da gruta Casa de Pedra, como articulações, reuniões técnicas e com autoridades locais, audiências públicas, relatórios técnicos, estudos, mapeamento e trabalhos de campo (SEMA, IPHAN e UFC), fiscalizações ambientais (SEMACE e BPMA), elaboração de projetos (SEMA, IPHAN e UFC), divulgação da gruta em entrevistas e reportagens em jornais, 


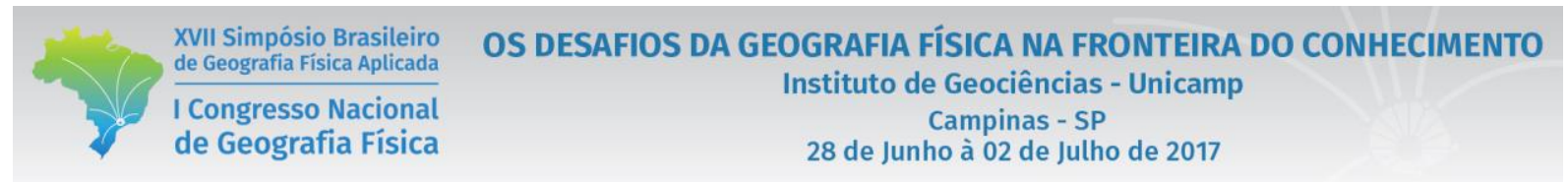

televisões e rádios, dentre outras atividades realizadas. Almeja-se no final deste complexo processo de proteção e recuperação do Patrimônio Espeleológico da gruta Casa de Pedra poder proporcionar a sociedade cearense mais um ambiente natural protegido e conservado, com informações sobre os estudos ambientais, arqueológicos e espeleológicos desta caverna, que possa se tornar uma verdadeira sala de aula natural, ensinando a importância de proteger este importante patrimônio.

\section{REFERÊNCIAS}

BRASIL. Constituição (1988). Constituição da República Federativa do Brasil - texto constitucional promulgado em 05 de outubro de 1988. Brasília: Câmara dos Deputados, 2012.

Decreto ${ }^{\circ}$ 99.556, de $1^{\circ}$ de outubro de 1990. Dispõe sobre a proteção das cavidades naturais subterrâneas existentes no Território Nacional. Diário Oficial [da] República Federativa do Brasil, Poder Executivo, Brasília, DF, 1 out. 1990.

. Decreto $n^{\circ} 6.640$, de 07 de novembro de 2008. Dispõe sobre nova redação para o Decreto no 99.556, de 01 de outubro de 1990. Diário Oficial [da] República Federativa do Brasil, Poder Executivo, Brasília, DF, 10 nov. 2008.

CONAMA. Resolução no 347, de 10 de setembro de 2004. Dispõe sobre a proteção do Patrimônio Espeleológico. Conselho Nacional de Meio Ambiente (CONAMA). Diário Oficial [da] República Federativa do Brasil, Brasília, DF, 13 set. 2004.

FERREIRA, C. F. Análise de impactos ambientais em terrenos cársticos e cavernas. In: IV Curso de Espeleologia e Licenciamento Ambiental. Brasília: Centro Nacional de Pesquisa e Conservação de Cavernas (CECAV) / Instituto Chico Mendes de Conservação da Biodiversidade (ICMBio), 2013.

MONTEIRO, Felipe A D. A Espeleologia e as Cavernas no Ceará: conhecimentos, proteção ambiental e panorama atual. 2014. Dissertação (Mestrado em Desenvolvimento e Meio Ambiente) - Universidade Federal do Ceará, Fortaleza, 2014. Disponível em: <http://www.repositorio.ufc.br/handle/riufc/15881>. Acesso em: 29 abr. 2016.

Patrimônio Espeleológico Brasileiro: Proteção, Licenciamento Ambiental e Destruição. In: VI Congreso Iberoamericano de Estudios Territoriales y Ambientales (CIETA), 2014, São Paulo-SP. Anais VI CIETA, $2014 \quad$ a. $\quad$ Disponível em: <http://6cieta.org/arquivosanais/eixo5/Felipe\%20Antonio\%20Dantas\%20Monteiro.pdf>. Acesso em: 29 abr. 2016.

O POVO. Caverna em Madalena. Gravuras podem ter 3 mil anos. Jornal O Povo, reportagem de 15/11/2015. Fortaleza, $2015 . \quad$ Disponível em: <http://www.opovo.com.br/app/opovo/dom/2015/11/14/noticiasjornaldom,3533717/caverna-em-madalena-gravuraspodem-ter-3-mil-anos.shtml>. Acesso em: 16 dez. 2015.

VERÍSSIMO, César; LIMA, Jefferson: CASTELO, Vanusa. Mapa de Registro de Cavidades Naturais - Casa de Pedra, no município de Madalena-CE. Fortaleza: Departamento de Geologia da Universidade Federal do Ceará (UFC), 2014. 